\title{
Histórias (in)visíveis: o medo pelo outro como um ato responsável
}

\author{
Ana Beatriz Ferreira Dias" \\ Valdemir Miotello"
}

\section{Resumo}

Ao problematizar relações sociais prejudicadas por danos ligados à prática de ato infracional, analisamos enunciados que circularam em uma prática de justiça restaurativa denominada "Círculo Restaurativo", uma prática bastante recente no contexto brasileiro. Com foco em enunciados proferidos pela mãe do jovem em conflito com a lei, exploramos a relação que ela estabeleceu com seu filho enquanto uma alteridade que lhe constitui e altera. Para tanto, analisamos a gravação em áudio e vídeo de um círculo restaurativo presente no acervo do projeto gaúcho Justiça para o Século 21. A metodologia de análise fundamenta-se em orientações teórico-metodológicas formulados pelo Círculo de Bakhtin, desenvolvidas de acordo com o paradigma indiciário de leitura e cotejamento de textos. Observamos que os enunciados da mãe do jovem infrator sugerem um forte medo pelo filho, de tal forma que sua percepção dos fatos a aprisiona em uma responsabilidade ilimitada por ele.

Palavras-chave: Ato responsável. Bakhtin. Justiça restaurativa.

\section{Introdução}

Ao questionarmos a noção saussuriana de língua como um todo por si, constituída por um conjunto de convenções arbitrárias de que se vale a massa de falantes para exercitar a linguagem, pode causar grande estranhamento essa autonomia da língua, como se ela pairasse sobre os falantes, que, passivamente, se apropriariam desse "tesouro depositado pela prática da fala em todos os indivíduos pertencentes a mesma comunidade", como propõe Saussure (2006, p. 21) em sua tarefa de delimitação de um possível objeto de estudo para a Linguística. Esse simples estranhamento

\footnotetext{
* Doutora em Linguística pela Universidade Federal de São Carlos (UFSCar). Professora Adjunta de Língua Portuguesa e Linguística no Curso de Graduação em Letras: Português e Espanhol - Licenciatura, da Universidade Federal da Fronteira Sul (UFFS), Campus Cerro Largo (RS). E-mail: ana.bdias@hotmail.com

** Doutor em Linguística pela Universidade Estadual de Campinas. É professor associado IV (aposentado) da Universidade Federal de São Carlos. Tem experiências na área de Linguística, com ênfase em Estudos Bakhtinianos. É líder do Grupo de Estudos dos Gêneros do Discurso - GeGe/UFSCar.
}

Data de submissão: abr. 2018 - Data de aceite: jun. 2018 http://dx.doi.org/10.5335/rdes.v14i2.8043 
da perspectiva estruturalista já aponta para uma certa radicalização em relação aos princípios fundantes da Linguística, ainda que reconheçamos as importantes contribuições do estruturalismo para o estabelecimento dessa área como uma ciência.

$\mathrm{Na}$ visão de Geraldi, a pesquisa em linguagem vem passando por um "rearranjo profundo em andamento que cruza, de alto a baixo, os programas de pesquisa e os modos de definir seus objetos, suas metodologias e seus parentescos disciplinares" (2010, p. 51). Nesse contexto, entendemos que integra tal reconfiguração de nosso campo de estudos a compreensão de que todo encontro de palavras não é unicamente um encontro entre os signos linguísticos que compõem um sistema, mas é, antes de tudo, um encontro entre sujeitos que têm, na língua, seu território comum, como apontam Bakhtin/Volochínov, em sua conhecida passagem que aborda a palavra como elo entre sujeitos: "a palavra é um espécie de ponte lançada entre mim e os outros. Se ela se apoia sobre mim numa extremidade, na outra apoia-se sobre o meu interlocutor" (2009, p. 117).

Partindo dos estudos bakhtinianos, Mello reitera que todo e qualquer encontro entre sujeitos é mediado pela linguagem, tanto que "não encontramos o outro diretamente, como a chuva encontra a terra" (2017, p. 25), como pode parecer aos nossos olhos. Mas, em um encontro entre eu e outro, existem pontes - existem os signos, esclarece a pesquisadora.
Um encontro de palavras é um encontro com o outro. Encontro com o diferente ou com o semelhante a mim, mas, também, encontro com o desconhecido e com aquele de meu cotidiano que, por alguma razão, tornou-se invisível. Em seu livro Procurando uma palavra outra, Ponzio (2010a) inclui nesse encontro, além da interação com outra pessoa, a relação do eu consigo mesmo.

Neste trabalho, abordamos um encontro de palavras no qual os sujeitos compartilham uma mesma realidade: estão envolvidos direta e/ou indiretamente em uma situação de conflito em que houve prática de ato infracional e buscam, por meio de um encontro face a face, encontrar alternativas para lidar com os danos que ocorreram às pessoas e às suas mais diversas relações ${ }^{1}$. Os danos produzidos por situações de violência podem ser altamente devastadores e traumáticos não só para os membros de uma sociedade, mas principalmente para vítimas e ofensores, bem como para seus familiares e amigos que vivenciam rompimento de vínculos, os quais podem ser acompanhados por uma série de sentimentos, como de medo, insegurança, vingança e vulnerabilidade. Como observa o professor e pesquisador em abordagens de justiça Howard Zehr, as situações de violência provocam "uma violação do ser, uma dessacralização daquilo que somos, daquilo em que acreditamos, de nosso espaço privado", abalando pressupostos essenciais para completude, mesmo que provisória da vida, como a "crença de que 
o mundo é um lugar ordenado e dotado de significado, e a crença na autonomia pessoal" (2008, p. 24).

O foco deste trabalho, recai, portanto, na problematização de um encontro entre sujeitos em que houve danos, neste caso, decorrentes do que o sistema oficial de justiça denomina de ato infracional. Para compreender aspectos da interação verbal que aconteceu entre os sujeitos como caminho para compreender relações sociais abordadas em sua singularidade, apresentamos aqui um estudo de caso voltado à análise de um círculo restaurativo, o qual é parte de um procedimento de justiça que se baseia em pressupostos teóricos e metodológicos da justiça restaurativa, uma abordagem bastante recente no contexto brasileiro que vem sendo utilizada para prevenir e resolver situações de violência em várias instâncias.

Fundamentado em valores de uma nova abordagem de justiça chamada de "justiça restaurativa" por estudiosos de áreas como Direito, Sociologia, Serviço Social e outras afins, o Círculo Restaurativo é entendido como parte de um procedimento restaurativo que conta com a participação de vítimas, ofensores, bem como de seus respectivos familiares, amigos e outras tantas pessoas consideradas como "comunidade de apoio", cuja participação seja aceita por aqueles mais diretamente envolvidos no dano. Conduzido por um coordenador e, algumas vezes, por um segundo coordenador, o encontro entre esses sujeitos são propostos com as finalidades de: criar um espaço de diálogo; buscar a compreensão dos acontecimentos passados e suas consequências na vida de cada um dos participantes; construir, em comum acordo (que pode ou não substituir a sentença do juiz), um plano de ações que contribua na redução dos impactos resultantes do dano; humanizar os sujeitos e suas relações.

Interessados no uso da linguagem em prática de justiça restaurativa, apresentamos aqui a leitura que realizamos, então, de um círculo restaurativo gravado em áudio e vídeo presente no acervo do projeto Justiça para o Século 21 (J21). Como discutiremos no próximo item, o J21 é uma iniciativa dedicada a divulgação e implementação de práticas restaurativas no Rio Grande do Sul (RS). Por meio da aprovação da proposta de pesquisa pelo J21 e na condição de parceiros individuais, foi possível o acesso à parte desse acervo, do qual selecionamos aleatoriamente um caso disponível para desenvolvimento deste trabalho, que é de natureza qualitativa ${ }^{2}$.

Diante da multiplicidade de sentidos que compõem esse círculo restaurativo, observamos a insistente recorrência de uma tensão que permeou esse encontro de justiça, e que foi adotado, neste trabalho, como objeto de análise: notamos que o discurso de uma mãe apresentou-se como inquieto, tenso e intranquilo devido ao encontro que ela estabeleceu com a alteridade, que, neste caso, é o seu filho em situação de conflito com a lei. Tendo 
essa interação verbal como o posto de observação para compreender o encontro de palavras, tomamos como fundamentação teórica central os estudos do Círculo de Bakhtin e de estudiosos que desenvolvem essa corrente de pensamento, como Geraldi, Petrilli e Ponzio.

Para buscar organizar nossas compreensões, apresentamos, a seguir, a materialidade de análise, quando também a contextualizamos como parte de um movimento internacional de justiça restaurativa. Em seguida, apresentamos a metodologia de análise que adotamos para compreender os enunciados do caso de justiça. A partir disso, partimos para a análise propriamente das materialidades, que está dividida em três partes: observamos primeiramente caraterísticas da interação da mãe do infrator com seu filho, que é construída discursivamente, conforme nossa leitura, como uma diferença que não é indiferente; em seguida, identificamos e discutimos o discurso de obsessão pelo outro, do ponto de vista do conceito bakhtiniano de "ato responsável” e, por fim, relacionamos essa responsabilidade da mãe com a relação que Ponzio (2012) entende como "medo pelo outro", relacionando-a com a noção de "refém", proposta por Lévinas.

\section{Breve contextualização}

Como mencionamos anteriormente, a materialidade discursiva central para desenvolver este trabalho é a gravação em áudio e vídeo de um círculo restau- rativo que compõe parte do acervo do projeto J21. Articulado pela Associação dos Juízes do Rio Grande do Sul (Ajuris) e contando com parceiros individuais e institucionais, o J21 é uma iniciativa considerada pioneira não apenas no Estado do Rio Grande do Sul, como também no Brasil por divulgar e implantar práticas de justiça restaurativa em várias instâncias, como em escolas, organizações governamentais e não governamentais, comunidades e no Sistema de Justiça da Infância e Juventude em Porto Alegre. Esse projeto, que já realizava ações em justiça restaurativa de maneira assistemática desde 2002, passou a se consolidar a partir de 2005 , quando uma série de fatores contribuíram para sua implantação. Dentre eles, destaca-se a criação de um projeto-piloto de abrangência nacional intitulado Promovendo Práticas Restaurativas no Sistema de Justiça Brasileiro, que teve como objetivo inserir, avaliar e adequar as práticas de justiça restaurativa no contexto social e jurídico brasileiro, pois o J21 foi selecionado para integrá-lo como uma das experiências pioneiras com a implantação da justiça restaurativa no sistema oficial de justiça ${ }^{3}$.

Com sua criação oficializada, o J21 passa a existir e, então, "é concebido executado no seio do poder judiciário gaúcho" (BRANCHER, 2008, p. 11), mais precisamente, na $3^{\text {a }}$ Vara do Juizado Regional da Infância e da Juventude de Porto Alegre ( $3^{\text {a }}$ VJRIJ), onde ficou sediado nos primeiros anos de suas 
atividades. Devido às experiências acumuladas, sobretudo daquelas ligadas à descentralização das atividades antes reservadas apenas ao projeto $\mathrm{J} 21 \mathrm{e}$, como consequência, ao empoderamento dos parceiros, o J21 e a $3^{\text {a }}$ Vara adquiriram significativa autonomia. Como uma das consequências disso, o projeto deixou de ser sediado no espaço da $3^{\text {a }}$ VJRIJ do Poder Judiciário de Porto Alegre e passou a exercer suas atividades em um lugar destinado unicamente a ele. Essas e outras mudanças contribuíram para que a $3^{\text {a }}$ Vara passasse a ser uma espécie de franquia do projeto J21, conforme afirmam Brancher \& Aguinsky (2007), adquirindo significativa autonomia e funcionando como se fosse uma "matriz" do projeto Justiça para o Século 21. Com isso, foi criada a Central de Práticas Restaurativas do Juizado da Infância e da Juventude (CPR/JIJ), que, inserida na $3^{\text {a }}$ Vara, passa a representar um ideal de exercício da justiça restaurativa em instância do poder judiciário. Desse modo, a CPR representa um ponto de encontro entre o J21 e a $3^{\mathrm{a}}$ Vara.

Ainda que tenha se dissociado da $3^{\mathrm{a}}$ Vara, o projeto J21 mantém o foco de sua atuação no sistema de justiça, tanto que afirma:

As iniciativas do Projeto têm sua inserção principal na rede de atendimento ao adolescente em conflito com a lei a partir do Sistema de Justiça, mas estabelece parcerias de forma que amplia sua abrangência, produzindo repercussões no âmbito de outras políticas como as de Segurança, Assistência, Educação e Saúde (JUSTIÇA PARA O SÉCULO 21, 2011)
Com forte atuação na divulgação da justiça restaurativa e na formação de agentes sociais para atuarem como coordenadores de práticas de justiça restaurativa, o J21 mantém-se, portanto, como importante e imprescindível parceiro da $3^{\text {a }}$ Vara, contribuindo desde a realização das práticas restaurativas até a avaliação e efetividade das práticas restaurativas. Cabe ainda destacar que, desde sua criação, o J21 incluiu em ações a elaboração, a organização e a sistematização de um acervo, que, além de construir as memórias da iniciativa, contribui para o desenvolvimento e a avaliação de suas práticas. Várias produções compõem o seu vasto acervo: desde materiais de divulgação (como folders e manuais), passando pela criação e manutenção do seu site institucional (que conta não apenas com informações sobre o movimento restaurativo e as atividades propostas pelo programa, mas também com uma biblioteca on-line), até gravações em áudio e vídeo dos casos de justiça restaurativa (que servem, sobretudo, para a avaliação das práticas restaurativas realizadas).

Analisamos, assim, um caso de justiça restaurativa inserido no sistema oficial de justiça. Caso Osório, como aqui intitulamos esse caso de justiça restaurativa, aconteceu como parte do processo judicial realizado pela $3^{\mathrm{a}}$ VJRIJ. $\mathrm{O}$ ato infracional praticado por Osório foi enquadrado, pela justiça tradicional (retributiva) como roubo, de modo que, para dar prosseguimento ao processo, o 
juiz responsável optou por encaminhar o caso, após audiência, para realização do procedimento restaurativo. $\mathrm{O}$ processo foi direcionado à Central de Práticas Restaurativas do Juizado Regional da Infância e da Juventude de Porto Alegre (CPR/JIJ), a qual oferece, desde 2005, táticas alternativas para resolução de conflitos no âmbito do sistema oficial de justiça.

As ações desenvolvidas pela CPR, assim como todas as experiências com justiça restaurativa que são pensadas, discutidas e propostas nas mais variadas instituições públicas e privadas são, de alguma maneira, expressões únicas e singulares de um amplo movimento de justiça restaurativa que surge, como observa Neto (2004, p. 36), internacionalmente enquanto uma "rede informal e descentralizada" voltada à divulgação e à implementação de valores e procedimentos da justiça restaurativa. Bastante atuante nos anos 1980, o movimento de justiça restaurativa só foi sendo realmente difundido a partir da década de 1990, quando passou por uma fase de grande expansão em várias partes do mundo. Nesse período, até mesmo a expressão justiça restaurativa começou a ter maior visibilidade. Cabe observar, porém, que terminologia "justiça restaurativa" parece ter surgido bem antes de tudo isso. De acordo com Jaccoud (2005), foi o psicólogo americano Albert Eglash quem cunhou, pela primeira vez, a expressão “justiça restaurativa”, a qual foi empregada em um artigo publicado em
1877 para referir a uma das três respostas ao crime: a retributiva, a distributiva e a restaurativa. Diante disso, podemos afirmar que a abordagem restaurativa de resolução de conflito permaneceu bastante silenciada até a década de 90 .

Ao propor o caminho da justiça restaurativa como um terreno para que os sujeitos lidem com os conflitos e seus possíveis danos, as iniciativas em justiça restaurativa, ainda que bastante heterogêneas entre si, normalmente convergem em relação ao entendimento que fazem da justiça retributiva (abordagem tradicional que conhecemos), pois questionam fortemente suas práticas, rechaçando-as normalmente. Como assinalam McCold \& Wachtel, a justiça retributiva responde às situações de conflito e violência com um alto controle sobre os sujeitos e com baixo apoio a eles, de tal modo que, ao conduzir todo o processo, "tende a estigmatizar as pessoas rotulando-as indelevelmente de forma negativa" (2003, p. 2).

Enquanto abordagem de justiça dominante em nossa sociedade, essa perspectiva de justiça tem sua mais alta expressão no sistema oficial de justiça, que fortemente se sustenta em pilares do Direito Penal. Nesse, os sujeitos diretamente envolvidos com atos infracionais são definidos e concebidos de acordo com uma, e apenas uma, dessas duas identidades: ou como vítimas ou como ofensores/infratores. Ancorados em códigos e normas jurídicas, operadores do direito categorizam sujeitos de acordo com uma dessas duas identidades, por meio de um processo de investigação. Nessa relação, 
as identidades estigmatizam, em geral, os sujeitos e exclui vários, principalmente quando se trata de práticas de justiça envolvendo vítimas e ofensores, ou seja, no sistema estatal de justiça.

Como observam os promotores de justiça Carvalho \& Lobato (2008), é notório e já conhecido o fato de o sistema penal atual despersonalizar os conflitos, pois concebe os sujeitos como representantes de papéis sociais no cenário jurídico. A pertença dos sujeitos a certas identidades fixa-os em determinadas posições, necessárias para a organização e o andamento das atividades do modelo de justiça tradicional. É preciso que o sujeito ocupe certa posição social, à qual se atribui um valor axiológico, para que exista a relação do tipo perde-ganha (para que um sujeito ganhe, o outro precisa perder), característica do sistema judiciário. Ainda nessa mesma direção, Sales (2007) afirma que o modelo tradicional de resolução de conflitos existente no Poder Judiciário possui inúmeras estratégias para que se instaure um contexto de disputa em que um sujeito ganha e o outro perde. Por isso, no sistema de justiça existem lados opostos, disputas, petição inicial, contestação, etc.

Mesmo que surja como uma alternativa ao modelo retributivo, experiências com justiça restaurativa reconhecem limitações em suas práticas. Ainda que pareça conceber as relações sociais sob um viés mais humano com sua outra abordagem de resolução de conflitos, "a justiça restaurativa não é um remédio para todos os males do modelo retributivo", sugere Neto (2000, p. 102). Ela surge no cerne de nosso paradigma atual, banhado no modelo retributivo, e nele se constitui, ainda que o questione e sua busca seja por superá-lo. Por si só, isso, porém, não determina a anulação de seus esforços no sentido de instaurar uma outra palavra, outra abordagem, no sistema oficial de justiça para responder às situações de crime e ao ato infracional.

Atuar no interior do sistema que questiona pode ser uma tática para implantar uma nova abordagem. Segundo Certeau (2011), a tática consiste na ação calculada e exercida por um sujeito destituído de poder em um lugar que não lhe é próprio. A tática se realiza em terreno alheio, por isso, ela deve jogar no lugar que lhe é "imposto tal como o organiza a lei de uma força estranha”. Usando as palavras de Bullow, Certeau afirma que a tática é movimento "dentro do campo de visão do inimigo" que se realiza no espaço por ele controlado. É no âmbito desse espaço hegemônico, mantido pelas estratégias de poder dos fortes, que a tática se exercita enquanto contrapalavra, operando da seguinte forma:

Ela opera golpe por golpe, lance por lance. Aproveita as “ocasiões" e delas depende, sem base para estocar benefícios, aumentar a propriedade e prever saídas [...]. Este não lugar lhe permite mobilidade, mas nunca docilidade aos azares do tempo, para captar no voo as possibilidades oferecidas por um instante. Tem que utilizar, vigilante, as falhas que as conjunturas particulares vão abrindo na vigilância do poder proprietário. Aí vai caçar. Cria ali surpresas. Consegue estar onde ninguém espera. É astúcia (CERTEAU, 2011, p. 94-95). 
Aproveitando determinadas frestas, aberturas, falhas no poder hegemônico, a tática acabando sendo movimento de surpresa e desvio à ordem do discurso. É estranhamento dentro do espaço de poder da ideologia que, no jogo social, foi a vencedora e se estabeleceu como dominante.

\section{Metodologia para compreensão da materialidade discursiva}

Para compreender aspectos da interação verbal presente em um círculo restaurativo, tomamos a palavra como unidade de análise, centrando as compreensões nos recursos expressivos mobilizados nos enunciados. Tendo isso em vista, focamos a análise na observação da seleção lexical, da sintaxe e de elementos prosódicos. A partir dos estudos bakhtinianos, abordamos esses elementos da língua em sua relação estreita e necessária com o contexto social mais amplo e imediato, do qual são inseparáveis. Desse seu vínculo com as realidades, a palavra não é um signo "neutro", destituído de visões de mundo, mas, sim, carregada de valorações e pontos de vista que denotam algo das relações sociais, apontando inclusive para transformações incipientes e quase que imperceptíveis, afinal
[...] [a palavra] constitui o meio social no qual se produzem lentas acumulações quantitativas de mudanças que ainda não tiveram tempo de adquirir uma nova qualidade ideológica, que ainda não tiveram tempo de engendrar uma forma ideológica nova e acabada. A palavra é capaz de registrar as fases transitórias mais íntimas, mais efêmeras das mudanças sociais (BAKHTIN/ VOLOCHÍNOV, 2009, p. 42).

A maneira como buscamos compreender as palavras foi construída a partir de uma atitude diante dos enunciados que envolveu o cotejamento entre textos (GERALDI, 2012) a ser realizado com base no paradigma indiciário de leitura (GINZBURG, 1989). O cotejamento, em síntese, consiste em colocar diferentes textos em relação uns com os outros. A compreensão dos enunciados será maior, mais profunda, na medida em que o pesquisador conseguir "ampliar os contextos", ou seja, fazer emergir "mais vozes do que aquelas que são evidentes na superfície discursiva" não para encontrar a "fonte do dizer", mas para fazer dialogarem textos, diferentes vozes". Dar contextos a um texto é, segundo pensador, "cotejá-lo com outros textos" (GERALDI, 2012, p. 29-33).

Com isso, o pesquisador retoma alguns nós interpretativos que compõem a cadeia infinita da comunicação entre enunciados, encontrando "enunciados a que o texto responde, a que se contrapõe, com quem concorda, com quem polemiza, que vozes estão aí sem que se explicitem porque houve esquecimento da origem" (GERALDI, 2012, p. 33). Neste trabalho, correlacionamos, então, diferentes textos 
que foram enunciados no círculo restaurativo, bem como cotejamos conceitos teóricos com as interações travadas nesse encontro de justiça restaurativo como caminho para aprofundar a leitura.

Exercitamos o cotejamento no terreno do paradigma indiciário de pesquisa proposto por Ginzburg (1989). Conforme essa orientação metodológica, o pesquisador, como um "detetive" que busca pistas para compreender os eventos, constrói sentidos e encontra possíveis respostas às suas questões, em um percurso interpretativo fundamentado em argumentos que justifiquem as leituras feitas. Em um amplo horizonte de possibilidades, os sentidos traçados em um trabalho registram uma opção possível dentre várias. Como Geraldi (2012), também consideramos que os sentidos construídos, ao longo de uma investigação, foram aqueles possíveis de serem traçados, com os dados disponíveis naquele momento da pesquisa.

Destacamos que nossas compreensões de textos revelam um esforço acadêmico para construir uma verdade possível, uma leitura fundamentada teórica e metodologicamente, e não uma verdade única sobre o tema. Como afirma Bakhtin, é um "triste equívoco, herança do racionalismo", supor que a "verdade só pode ser a verdade universal [istina] feita de momentos gerais, e que, por consequência, a verdade [pravda] de uma situação consiste exatamente no que esta tem de reprodutível e constante" (2010, p. 92-95). Para o pensador russo, a verdade- pravda pode ser compreendida como a verdade daquele viver-agir único e singular, sendo que "a inclusão responsável na singularidade única reconhecido do ser-evento é o que constitui a verdade-pravda da situação". É por esse viés de verdade que construímos o fazer científico. Iniciemos a compreensão dos enunciados referentes à relação entre mãe e filho por meio da observação de características que, naquele contexto, remete a uma verdade-pravda que deixa marcas na língua.

\section{De uma atenção amorosamente interessada}

Em nosso exercício de escuta das palavras que circulam neste círculo restaurativo, encontramos em Irene uma capacidade de se envolver ativa e responsavelmente com Osório, seu filho que praticou um ato infracional. Tendo em vista os estudos elaborados pelo Círculo de Bakhtin, consideramos que o envolvimento dessa mãe com o filho carrega um amor eticamente produtivo.

Para Bakhtin (2010), apenas uma relação desinteressada - daquelas cujo envolvimento não se pauta no que o outro pode me oferecer por suas qualidades e virtudes, mas, sim, da relação de único para único - é capaz de afirmar e consolidar a diversidade e a diferença, sem esquematizar ou enquadrar o sujeito em categorias abstratas. Nas palavras do pensador: 
Somente uma atenção amorosamente interessada pode desenvolver uma força muito intensa para abraçar e manter a diversidade concreta do existir, sem empobrecê-lo e sem esquematiza-lo. Uma reação indiferente e hostil é sempre uma reação que empobrece e desintegra o objeto: passa longe do objeto em toda a sua diversidade, o ignora e o supera (BAKHTIN, 2010, p. 128)

Trata-se de uma vivência capaz de colocar, no horizonte das possibilidades, uma relação com um outro diferente de mim que se apresenta com seu mundo socialmente valorado que posso ou não concordar, polemizar e discordar. Notamos que o discurso da mãe apresenta-se como inquieto, tenso e intranquilo devido ao encontro que ela estabelece com a alteridade, com o outro fora dos lugares tradicionais de infrator, de filho, de menor em conflito com a lei, de adolescente ou quaisquer outras tentativas de encerrar o outro, Osório, em identidades. A força centrífuga da alteridade desconcerta a constituição do eu - é isso que o discurso de Irene nos mostra em relação a Osório, um outro sujeito que é a concreta materialização, do ponto de vista de Irene, da alteridade.

$\mathrm{O}$ fato de o comportamento do filho lhe alterar pode ser percebido nas próprias enunciações desta mãe. Ainda que o conflito seja (re)vivido de diferentes maneiras por ela ao longo do procedimento restaurativo, Irene assume inegavelmente uma posição de não-indiferença que deixa marcas em seu discurso. A seguir, destacamos construções linguísticas empregadas na prática restaurativa para, então, começarmos a apontar para o uso concreto da língua, inseparável do meio social e da valoração atribuída a esse contexto pelo enunciador:

\section{(1)}

Coordenador - E eu queria pedir pra Irene falar um pouquinho, assim, dessas consequências da situação... pra ti, assim.

Irene - Pra mim, mudou totalmente a minha vida, né [...] Então, no dia em que eu soube que aconteceu isso aí, eu enlouqueci dentro de casa. Eu não conseguia falar com ninguém [...] E acabou comigo na hora né.

Coordenador - Hoje, como é que tu te sente em relação a isso. $O$ que mudou hoje pra ti?

$$
\text { Irene - Mudou tudo [...] }
$$

Nesse encontro de palavras, podemos observar que Osório é, do ponto de vista de Irene, uma alteridade que a invade, desconcerta-a, desacomodando seu lugar na relação que mantinha com ele e com a própria vida. Considerando o valor semântico dos adjuntos adverbiais que acompanham o verbo mudar, podemos afirmar que a prática do ato infracional foi, para a mãe, uma grave experiência que transformou significativamente seu viver-agir: "mudou totalmente" e "mudou tudo". Além desses itens lexicais em destaque, cabe assinalar outras duas estratégias discursivas que apontam para a valoração negativa do fato na vida da enunciadora, segundo a perspectiva construída em seu discurso. 
Uma dessas estratégias é o emprego dos seguintes verbos que atribuem destruição e assolamento a sua vida por saber que o filho praticou um ato de violência: "eu enlouqueci" e "acabou comigo". A hipérbole, nessas duas construções linguísticas, oferece ao enunciado um modo de dizer que causa mais intensidade ao sofrimento. A outra estratégia refere-se a prosódia de Irene. Por mesclar-se ao choro, a voz trêmula, que vagarosa e pausadamente enuncia, remete a uma alta carga emocional ligada à tristeza e ao sofrimento.

Antes ainda de desdobrarmos a análise à compreensão de outros elementos, cabe uma última observação a respeito desse trecho (1). É importante levarmos em conta que, mesmo sendo um trecho relativamente curto, esse encontro de palavras serve já para apontar o tipo de relação que sujeitos da comunidade de apoio estabelecem com Osório, pois toda e qualquer palavra, quando enunciada, é uma pista da posição que o sujeito assume diante do conteúdo em questão. Enunciar é já se posicionar. De acordo com Bakhtin, a palavra viva, plena, quando diz respeito à experiência vivida em sua eventicidade irrepetível, dá existência ao objeto, ao sujeito e destina a ele uma atenção não indiferente.

Conforme a perspectiva bakhtiniana, pronunciar uma palavra significa estabelecer uma relação interessada e afetiva com o outro, mesmo que criemos estratégias de neutralidade para não nos desnudarmos:
Pelo simples fato de que eu comecei a falar dele, já entrei em uma relação que não é indiferente, mas interessado-afetiva e por isso a palavra não somente denota um objeto como de algum modo presente, mas expressa também com a sua entonação (uma palavra realmente pronunciada não pode evitar de ser entoada, a entonação é inerente ao fato mesmo de ser pronunciada) a minha atitude avaliativa em relação ao objeto - o que nele é desejável e não desejável - e, desse modo, movimenta-o em direção do que ainda está por ser determinado nele, torna-se momento de um evento vivo (BAKHTIN, 2010, p. 86-87).

Desse modo, a palavra é uma resposta, valorativa e não indiferente ao outro, à sua singularidade única e insubstituível. No que diz respeito ao caso de justiça restaurativa que aqui compreendemos, a resposta de Irene constrói a ideia de que o comportamento do filho não apenas lhe desagradou, como foi prejudicial e devastador para sua vida. E não apenas isso. Essa resposta da mãe ao filho revestiu-se, ainda, de uma responsabilidade ilimitada como insuportável obsessão pelo outro. É sobre essa responsabilidade, como um não-álibi frente ao acontecimento, que discorremos no próximo item.

\section{Responsabilidade} ilimitada como

\section{insuportável obsessão pelo outro}

Osório envolveu-se em uma situação de violência: durante uma situação de roubo, agrediu fisicamente a vítima. A justiça retributiva respondeu a isso, atri- 
buindo a Osório uma medida socioeducativa, a qual é aplicada a sujeitos menores de 18 anos, considerados penalmente inimputáveis. Nesse contexto, notamos que sua mãe assume um lugar, no diálogo, que é de inteira responsabilidade por ele, contudo, é uma responsabilidade que excede a meros cumprimentos de papéis sociais considerados desejáveis e aponta, ao invés, para uma resposta única e singular frente a esse outro que a sociedade, de maneira geral, identifica-o apenas como ofensor/agressor.

Neste círculo restaurativo, não encontramos como predominante uma responsabilidade abstrata, referente ao papel ou à função tradicionalmente atribuída a uma Mãe, cuja identidade a obrigaria a responder de uma e não de outra maneira diante do conflito em que seu filho esteve envolvido. Com base nos estudos bakhtinianos, especialmente aqueles desenvolvidos por Augusto Ponzio, entendemos que esse tipo de responsabilidade relativa a identidades, que é resultante da pertença do sujeito a grupos (de mães, de filhos, de infratores, etc.), tende a anular a singularidade do sujeito e barrar a enunciação de suas outras palavras, mais livres das amarras e cerceamentos sociais.

No caso dessas responsabilidades que são necessariamente atreladas a identidades, as enunciações são aquelas esperadas pela pertença do sujeito a um dado grupo social. Comporta-se de uma maneira, em detrimento de outra, porque integra dado grupo social. Bakhtin atribui essa responsabilidade típica de identidades (chamada por ele de "responsabilidade especial"), quando restrita a ela própria, ao mundo abstrato, teórico. A questão é que nesse mundo delimitado não é possível um ato responsável, único e singular do eu, afinal

[...] nele não é possível viver, agir responsavelmente, nele não sou necessário, nele, por princípio, não tenho lugar. O mundo teórico se obtém por uma abstração que não leva em conta o fato da minha existência singular e do sentido moral deste fato, que se comporta "como se eu não existisse" [...]; e tal conceito de ser, que é indiferente ao fato, para mim central, da minha encarnação concreta e singular no existir (aí estou também eu), não pode, por, princípio, acrescentar nada a ele, nem tirar nada dele, já que este mundo teórico permanece igual e idêntico a si mesmo no próprio sentido e significa, exista eu ou não (BAKHTIN, 2010, p. 52).

Já o lugar onde exerço meu viver-agir, se assentado do meu lugar único e insubstituível, desloca-se para o campo da responsabilidade moral, na visão desse pensador russo. Nesse campo, tem lugar aquela responsabilidade especial, delimitada, mas ela é apenas um momento do meu viver agir. Estamos diante do mundo da vida que é interpenetrado pelo mundo da cultura. De acordo com essa perspectiva, $o$ ato responsável do sujeito acaba sendo bidirecional porque refere-se tanto à responsabilidade especial quanto à responsabilidade moral. Desse ponto de vista, responsabilidade especial e moral estão entrelaçadas, portanto. Mesmo que, para fins de compreensão do ato responsável, Bakhtin estabeleça diferenças entre essas duas abordagens 
de responsabilidade, a especial e a moral não estão separadas uma da outra: elas se encontram em um único plano - no viver-agir do sujeito. Disso que destacamos, importa-nos centrar na ideia de que a responsabilidade especial não é suficiente para nos relacionarmos com aquilo que é único no mundo. É o diálogo como impedimento de o sujeito se encerrar na sua identidade que, na verdade, "me coloca diante do outro sem limites, sem possibilidades de dizer que sou responsável daqui até ali”, indo além da responsabilidade especial, afirma Ponzio (2012, p. 50).

É dessa posição de diálogo, como puro envolvimento com o outro, que Irene se relaciona com seu filho Osório. É no diálogo, particular de certa relação social, que uma responsabilidade especial de mãe parece ser incorporada por Irene na unidade do seu ser enquanto um momento de sua atividade responsável exercida na relação com Osório. Trata-se de se apresentar e se constituir como uma determinada mãe no evento singular, irrepetível, participativo e não indiferente do viver-agir. Não podemos negar: no círculo restaurativo, Irene apresenta-se e é identificada, por ela e outros sujeitos, como a mãe de Osório. Porém, a responsabilidade determinada pelo papel de mãe não dá conta da plenitude das vivências de Irene: é apenas um momento experimentado de certa maneira no âmbito de sua responsabilidade absoluta, moral, com e pelo Osório.
Tendo em vista o círculo restaurativo como uma prática comunicativa, consideramos que sua responsabilidade comporta uma responsabilidade sem álibis, sem a desculpa de que não deve ou não pode ocupar o seu lugar no mundo, que é único e se refere ao mundo da vida. A palavra de Irene é um responder e um responsabilizar-se. Como assinala Ponzio, o diálogo no sentido bakhtiniano "é a responsabilidade e um responder do outro" (2012, p. 50). Percebemos que essa estrutura dialógica do eu, de envolvimento intenso com a alteridade, materializa-se, neste caso, em um discurso que é de obsessão pelo outro. Em Irene, encontramos uma outra palavra que evidencia uma certa responsabilização sem limites de tempo e de espaço que marca esta relação de singular com singular. Notamos que, ao longo do círculo, essa participante fala que se sente em uma relação de inevitável envolvimento com Osório que faz com que ela responda com um comportamento de obsessão por ele, marcado pelo medo que sente pelo filho.

Irene tem consciência da relação de não indiferença que instaura com Osório, e o seu discurso mostra que ela não vê saídas para aliviar o peso que a alteridade necessariamente lhe provoca. Daí, emerge sua tensão e desassossego. Observemos a inquietação de Irene materializada em seu discurso, tendo em vista a seguinte interação social mais imediata que ela estabelece como resposta à pergunta do coordenador do procedimento. $\mathrm{O}$ tema da conversa trata, 
assim como no trecho 1, das consequências do ato na vida da mãe desse infrator:

Irene - [...] Eu não me sinto segura. Eu não deixo nem ele ir no bar sozinho... Eu tenho medo. Eu tenho medo pelas companhias. Eu tenho medo pela polícia.

Coordenador - Tem medo de represália?

Irene - Tenho. Eu... eu... me sinto presa a ele. Eu não deixo ele sair. Ele só sai comigo ou com a vó dele ou com o pai dele. Ele não sai pra lugar nenhum, sem ser com nós. Tanto que nem na escola eu tô deixando ele ir. Não deixo mais ele nem mais estudar, até conseguir a transferência onde eu possa levar ele na escola e ir buscar.

Coordenador - Tá te sentindo insegura?

Irene - Tô.

Coordenador - Precisando de...

Irene - Falta de confiança, que eu não tenho confiança nele mais. $\mathrm{E}$ o que eu espero que é ele possa fazer a gente sentir confiança nele de novo. [...] Até eu pegar confiança nele, sabe, eu não sei... Eu não vou conseguir sossegar assim ou me deitar tranquila, achando que ele tá bem. Só sei que ele tá bem quando ele tá com a vó dele. - "Ai, eu vou lá pra vó, eu vou ficar lá na vó." - "Ah, então tá, fica lá na tua vó. Eu sei que tu tá lá na tua vó." Agora noutro lugar que ele vá, eu vou junto. Eu sempre vou ter que ir junto [...]. (Caso Osório)
Com base na interação verbal citada, podemos notar que Irene respondeu à situação de violência por meio de um ato que consistiu em limitar as saídas dele, como fica evidente no trecho acima, principalmente na asseveração: "Eu não deixo ele sair. Ele só sai comigo ou com a vó dele ou com o pai dele. Ele não sai pra lugar nenhum, sem ser com nós”.

Podemos dizer que, porque sofre pelo filho, tem medo pelo filho, a mãe assume a decisão de limitar a liberdade desse sujeito. Independente de uma possível valoração, em termos de "certo" e "errado" sobre essa opção de Irene, o importante aqui é sublinhar que ela não criou álibis: realizou um passo, tomou uma determinada atitude frente à situação do filho. Assumiu seu ato responsável, com sua verdade singular. E álibi, como esclarece Ponzio, significa "sem desculpas', 'sem escapatórias', mas também 'impossibilidade de estar em outro lugar', em relação ao lugar único e singular que ocupo no existir, existindo, vivendo" (2010b, p. 20). De sua participação singular na vida de Osório, ela adotou, portanto, um ato como sua própria resposta à situação de violência.

O outro lhe provoca uma reação de extrema novidade, e ela reconhece a obsessão por esse sujeito. Nos enunciados abaixo, retirados do segmento 2, o advérbio "nem" funciona com um operador argumentativo que sugere $o$ grau elevado, ou seja, o limite máximo da posição assumida por Irene em relação aos fatos, indicando a gravidade de suas ações, reconhecida como tal por ela: 
(2a)

- Eu não deixo nem ele ir no bar sozinho

- Ele não sai pra lugar nenhum, sem ser com nós. Tanto que nem na escola eu tô deixando ele ir

- Não deixo mais ele nem mais estudar, até conseguir a transferência onde eu possa levar ele na escola e ir buscar

A construção de sentido desses três enunciados conta com a existência, pressuposta no texto, de uma espécie de hierarquia de atos dispostos em uma escala, cujos pontos mais altos são justamente esses verbalizados pela enunciadora. Tamanho é o medo pelo filho que a mãe chega a nem deixá-lo ir ao bar sozinho e nem à escola e, consequentemente, nem estudar: essas são as atitudes que representam o ponto máximo que a relação com o fillho alcançou. Essas são, portanto, consequências do dano dotadas de significativa gravidade, do ponto de vista axiológico do eu enunciador.

Não podemos deixar de notar que a maneira como Irene responde à situação de violência, cerceando, em grande medida, a liberdade do filho, não é tranquila e serena, mas sim prenhe de uma imensa angustia e aflição porque diz respeito, podemos afirmar, a um envolvimento com a alteridade, afinal essa mãe ocupa uma posição de responsabilidade insuportável, sem limites, por esse filho, tanto que ela se sente, segundo suas próprias palavras, "presa" a ele. Essa inquietação decorrente de seu envolvimento com o outro fica evidente, ainda, na entonação de sua voz. A participante enuncia as palavras com voz trêmula, o que sugere uma alta carga emocional, do campo da tristeza, na composição de sua entonação.

Ainda no trecho 2, cabe retomar uma outra sequência da fala de Irene que, com características prosódicas que também sugerem tristeza e angústia, é enunciada com certos paralelismos que reforçam o valor semântico do conteúdo da fala, enfatizando, portanto, desassossego da enunciadora.

\section{(2b)}

Irene - Eu tenho medo. Eu tenho medo pelas companhias. Eu tenho medo pela polícia. (Caso Osório)

Enquanto uma forma simétrica entre elementos do enunciado, o paralelismo diz respeito a repetições de estruturas. No segmento supracitado, notamos três formas de paralelismo: sintático, semântico e rítmico. Interligados entre si na composição do enunciado, esses recursos não apenas determinam o sentido da ideia, mas principalmente tornam a construção mais enfática, indicando um maior valor ideológico presente no segmento.

O paralelismo sintático pode ser observado pela construção de três orações, todas coordenadas. A semelhança sintática entre elas também pode ser observada pelos mesmos léxicos que ocupam a posição inicial das três orações: todas iniciam com a construção linguística “eu tenho medo". É importante notarmos 
que está correlacionado a esse recurso um outro paralelismo, o rítmico. As três orações apresentam duração (extensão prosódica) muito próximas, afinal são compostas pelo mesmo sintagma, "eu tenho medo". Não há, nesse caso, significativas variações melódicas entre

(2c)

A - Eu tenho medo

B - Eu tenho medo pelas companhias.

$\mathrm{C}-\mathrm{Eu}$ tenho medo pela polícia. as entonações das orações. Esse tipo de paralelismo referente à extensão igual ou quase igual de certos segmentos é conhecido como "isocronismo".

Tendo em vista tudo isso, temos as seguintes construções:

Orações coordenadas
Conforme nossa leitura, toda essa reiteração no campo da língua não tem um fim em si mesmo. Entendemos que existe, nos referidos paralelismos sintático e rítmico, um paralelismo semântico na medida em que enfatizam um dado sentido, o estado de medo da enunciadora. A repetição de construções, nesse caso, está ligada ao existir-evento irrepetível e singular de Irene, pois esse modo de dizer reforça, com intensidade, o medo como a grande inquietação do seu ser. $\mathrm{O}$ importante são as vivências desse sujeito, que encontraram, na língua, táticas de dizer para construir, com força valorativa, a sua maneira de estar no conflito e agir diante dele. É importante ressaltar que, em outros tantos momentos da interação que não apenas essa situação de comunicação transcrita e discutida aqui, Irene mantém o estilo de construir paralelismos para intensificar o medo como a sua resposta aos conflitos. $\mathrm{Na}$ seguinte fala, por exemplo, está explícito outro enunciado no qual a mãe do infra- tor significa a situação de violência por esse viés do medo: "A gente tem medo. A gente tem medo pelas companhias. A gente tem medo pelo que aconteceu [...]. A gente tem medo. A gente tem medo pelas amizades".

Para compreendermos um pouco mais a relação com a alteridade, é fundamental ainda discutir uma dimensão da vivência de Irene que especifica o tipo de medo que ela sente. No próximo item, centramos a compreensão em torno da discussão do conceitos de "medo do outro" e "medo pelo outro".

\section{$\mathrm{O}$ medo pelo outro e a posição de refém}

Entendemos que a característica peculiar do seu medo está subentendida em complementos nominais preposicionados, que acompanham o vocábulo medo para delimitá-lo: "eu tenho medo pelas companhias" e "eu tenho medo pela polícia”. Esses enunciados de Irene apre- 
sentam, portanto, um outro paralelismo sintático e semântico (esse referente a posição sintática de complemento), que igualmente merece atenção para compreendermos elementos do encontro de palavras nesse círculo. Ambos os complementos determinam a natureza do medo.

Tendo em vista o valor semântico da preposição "por", que está contraída com artigos "a(s)" - "pela(s)" -, consideramos que a origem do medo parece ser o tipo de relação amorosamente estabelecida com o filho. Receia a polícia e as companhias do filho porque, antes de tudo, preocupa-se ativamente com ele. Conforme essa leitura, a relação central que leva à percepção do conflito é o envolvimento, participativo e desinteressado, entre essa mãe e esse filho, entre singulares.

Diante dessa interação, podemos afirmar que Irene aproxima-se de uma lógica contra-hegemônica sobre maneiras de lidar com conflitos em nossa sociedade. Para discutirmos isso, parece-nos interessante retomar aqui a ideia de diálogo elaborada por Ponzio (2012) e Petrilli (2013), mais precisamente, a leitura que esses pensadores fazem da obra de Lévinas para tecerem suas próprias concepções de diálogo.

O medo do outro, típico de relações sociais vivenciadas há séculos em nossa sociedade, diz respeito ao receio, ao pavor, de que o outro invada o meu espaço monológico e fechado. Esse é o modo de vida hegemônico. É medo de que o outro, fora de mim, atravesse os limites e rompa, de alguma maneira, com a totalidade do meu ser. Petrilli (2013) esclarece que o medo do outro nos faz conhecer relações sociais centradas na identidade e, como tal, esse medo é uma experiência ligada à necessidade de excluir o outro da vida do eu:

O medo do outro, o medo do qual se faz experiência o sujeito em relação ao outro, deriva da constituição da identidade que, seja essa individual ou coletiva, requer a separação do outro e a delimitação dos interesses da identidade [...]. Esses limites são estabelecidos pela identidade e constituem o fundo do qual emerge o medo no sujeito do outro. Tal situação leva ao reconhecimento do outro como necessidade imposta pelo medo que o outro possa violar o espaço da própria identidade, qualquer que essa seja, medo tão mais forte quanto mais forte é o esforço de excluir o outro (PETRILLI, 2013, p. 215).

Diferente disso é o medo pelo outro, que é responsabilidade pelo outro, diante do outro, assevera Ponzio (2012). É um medo outro que carrega vivências no âmbito do humanismo da alteridade. Tendo como foco a relação entre Irene e Osório, podemos afirmar que não predomina, em relação ao modo como a mãe se sente, um medo de Osório e nem um intenso medo da polícia ou das companhias em si - o seu "eu identitário" não foge amedrontado de nenhum deles. Nada disso predomina no seu discurso. Seu medo, ao invés, é responsabilidade, envolvimento, com o outro. A sua preocupação é com o filho, é o medo por ele, um medo pelo que ele possa sentir ou passar. Isso é posto em evidência no seu discurso. A posição de não indiferença faz com que ela sinta medo por ele. O sentimento da mãe centra-se no filho, em possíveis 
situações que esse possa, talvez, passar. É a instabilidade do ser humano, do filho principalmente, que lhe assusta. Irene, em seu dever de responder a Osório, tem medo por ele, preocupa-se obsessivamente com o que possa ou não acontecer com esse filho. Necessita saber onde e com quem ele está, sofrendo por isso. Assim, em sua memória de futuro, a mãe atemoriza-se pelo futuro do filho. O seu presente, tempo da enunciação, está carregado de memórias de futuro povoadas de medo pelo filho.

A partir das interações verbais estabelecidas no círculo, notamos que, na visão de Irene, Osório não lhe responde adequadamente, não lhe dá nenhuma resposta diante de toda a problemática do conflito e perante toda a obsessão dela por ele. Isso porque, em casa, o adolescente faz a opção pelo silêncio, que, conforme interpretação da mãe, sinaliza indiferença, não responsabilidade para com ela. Tanto é assim que, em dado momento do encontro, a mãe assinala que, em casa, o filho mantém-se em silêncio e não fala com ninguém acerca dos acontecimentos. Ela acredita, então, que, durante aquele encontro de justiça restaurativa, Osório talvez queira enunciar algo e propõe que o jovem fale das motivações que o levaram a se envolver na situação de violência. Com isso, a mãe atesta a sua necessidade pela palavra do filho, palavra que seria uma resposta possível diante das vulnerabilidades que ela mesma assume com o seu desassossego pelo filho.
Partindo do ponto de vista construído discursivamente por Irene, é possível afirmar que Osório, por não responder a ela, não assume a sua responsabilidade pela inquietação da mãe. Ela se desespera, preocupa-se com ele e assina a necessidade que tem dele e de sua palavra; Osório, por sua vez, encerra-se em si próprio, negando qualquer atividade verbal enquanto responsabilidade instaurada com a mãe. Esta é a verdade [pravda] de Irene: ela se sente insuportavelmente responsável por Osório e este, ainda do ponto de vista da mãe, nega-se a ter qualquer responsabilidade. Não há, portanto, reciprocidade.

Diante disso e com base na compreensão de Ponzio (2012) acerca dos estudos de Lévinas, podemos considerar que Irene torna-se, sobretudo, "refém" de Osório. Ponzio esclarece que Lévinas entende por refém uma situação "assimétrica” com o outro porque não tem, necessariamente, reciprocidade: "eu sou responsável pelo outro, e isso não significa que o outro seja responsável por mim”, esclarece Ponzio (2012, p. 58). Lévinas considera essa relação de "divisão desigual", em que apenas eu me sinto responsável pelo outro, como a verdadeira situação originária do homem, a sua condição primeira, que faz, inclusive, com que eu me sinta responsável pela responsabilidade do outro. É essa responsabilidade ilimitada e espontânea, sem a necessidade de receber algo em troca, que viabiliza o medo pelo outro. Ao correlacionarmos os estudos de Lévinas 
com o pensamento bakhtiniano, podemos entender que a situação de refém pode ser entendida, portanto, como uma resposta à situação de conflito, sendo um ato responsável de dado sujeito.

Em sua concepção de diálogo social, Ponzio (2012) conta com a ideia de que a justiça, na visão de Lévinas, surge para dar um pouco de paz ao sujeito que está envolvido com o outro em uma situação de insuportável responsabilidade não recíproca. A maneira como Lévinas encara a justiça é, para Ponzio, fundamental para compreender o diálogo social. Desse ponto de vista, a justiça é uma prática que pode libertar, em alguma medida, o sujeito da (in)condição de sentir-se sufocado pela sensação de estar refém de alguém.

Segundo Lévinas, a justiça, e também o Estado e a política, nasceram para aliviar o medo pelo outro, "para dar-me, em suma, um pouco de paz, para compreender até onde e até quando sou responsável”. A justiça não é, porém, a situação originária. A responsabilidade sem limites, sem horários, que marca a alteração do eu, a sua abertura ao outro, que pode ser carregada de sofrimento pelo eu, é, ao invés, a situação primeira, original. Acontece que a justiça surge diante dessa incômoda responsabilidade pelo outro para que exista alguma reciprocidade: "por que eu devo ser responsável por ti e tu não deves ser responsável por mim?" e "por que devo ser responsável por todos?" (PONZIO, 2012, p. 59).
Tendo em vista que "é preciso pensar o homem a partir da condição - ou da incondição - de refém" (LÉVINAS, 1993, p. 106), podemos afirmar que o círculo restaurativo permite a escuta dessa situação de estar refém de alguém. Notamos uma certa (in)condição do eu singular que, na relação única com o outro, desconcentra-se tamanha a força da alteridade, que impede o fechamento do eu na sua segura identidade.

Diante desse inquieto aprisionamento, o sujeito pode tentar encontrar táticas para aliviar o forte elo que o liga necessariamente a outros sujeitos. Em relação a esse círculo restaurativo que estamos buscamos compreender, notamos que Irene tece, desde o início do procedimento e na relação com os participantes, uma alternativa para construir alguma paz e tranquilidade frente a esse conturbado encontro com o outro. Para aliviar a situação de estar refém de Osório, Irene afirma a necessidade, anteriormente assinala por nós, de ter o conhecimento e o controle acerca de onde e com quem está o filho.

Mais especificamente, ela consegue mitigar, em alguma medida, o medo pelo outro, e ter instantes de sossego, quando o filho está ou fisicamente próximo dela ou acompanhado pela avó e/ou ainda pelo pai. Podemos afirmar que o comportamento de Osório é concebido pelos familiares como estranho, outro, porque é, neste caso, imprevisível e instável para eles. Não confiam nos atos do jovem, que já se envolvera duas vezes em situações 
de conflitos classificadas, pela justiça penal, como atos infracionais. Observemos o seguinte trecho, também presente na interação verbal descrita anteriormente (em 2), no qual Irene responde a questões proposta pelo coordenador. Nesse enunciado proferido por Irene, a enunciadora incorpora o discurso de outrem em sua palavra própria:

Irene - Só sei que ele tá bem quando ele tá com a vó dele. Ai eu vou lá pra vó, eu vou ficar lá na vó. Ah, então tá, fica lá na tua avó. Eu sei que tu tá lá na tua vó. Agora, em outro lugar que ele vá, eu vou junto. Eu sempre vou junto.

Esse enunciado, proferido por Irene, carrega um diálogo a duas vozes, a sua e a de Osório. Ela simula uma conversa com o filho: este comunica àquela que vai estar na casa da avó; e a mãe, por sua vez, responde a esse enunciado com a verbalização de sua tranquilidade com o comportamento dele. Dispostos do enunciado de um sujeito, réplicas estão em harmonia porque representam uma situação de consenso entre os sujeitos "envolvidos" no diálogo. Assim, a palavra reportada, no encontro com a palavra própria, faz ressoar uma vivencia ideal, do ponto de vista da enunciadora, que cria uma determinada perspectiva acerca do filho. Desse modo, o enunciado expressa um projeto de dizer concreto cuja direção ideológica parece apontar para a maneira como a enunciadora pensa $o$ conflito e parece sugerir uma necessida- de a ser atendida, no processo de justiça, para aliviar o peso da alteridade em sua vida. Para tanto, insere a voz de outro no seu próprio discurso, sinalizando como ela se sentiria segura e confortável.

É fundamental levar em consideração que o encontro, em um mesmo enunciado, da palavra própria com a palavra reportada está dialogicamente relacionado a outros textos. O enunciado citado, assim como qualquer outro enunciado, não existe por si, mas tem existência na relação que estabelece com outros enunciados, afinal, todo texto, seja escrito, seja oral, está sempre conectado com outros tantos textos. Em relação a essa natureza do enunciado, Ponzio ressalta que todo texto "está pensado em consideração a outros possíveis textos que este pode produzir; antecipa possíveis respostas, objeções, e se orienta em direção a textos anteriormente produzidos, os quais aludem, replicam, refutam ou buscam apoio, aos que congregam, analisam, etc." (2008, p. 101).

Tendo em vista o contexto de enunciação deste círculo restaurativo, podemos afirmar que o enunciado a duas vozes expresso por Irene é marcado, sobretudo, pela necessidade de amenizar a instabilidade que o outro lhe causou. Com várias táticas discursivas, esse sujeito afirma, para todos os sujeitos presentes no encontro, a sua necessidade de um movimento que minimize a invasão ao seu eu provocado por outrem. O outro o destruiu, tornando-o incompleto, tanto que agora deseja construir possíveis 
caminhos que sejam capazes de mitigar o sofrimento pelo medo que sente. Quer paz à inquieta e barulhenta responsabilidade pelo outro, que lhe atormenta. Quer que o filho fique mais em casa com ela e que ele exerça sua liberdade nas ruas acompanhado por determinados sujeitos - a mãe, a avó e o pai.

Com isso, Irene afirma que conseguiria ter instantes de sossego devido à (ilusória) crença de que os caminhos podem ser estáveis e conhecidos, e o que o outro sempre vai corresponder aos seus anseios para amenizar a relação com essa alteridade que altera a sua vida. No que tange a maneira como esse discurso ressoou, no momento do procedimento referente a construção do acordo entre as partes, apenas sublinhamos que podemos encontrar a combinação de certos atos centrados no comportamento de Osório que devem servir para dar sossego a sua mãe. Como ressoou o discurso de Irene no estabelecimento de acordos ao final do procedimento de justiça não é, contudo, o objetivo do presente trabalho.

\section{Considerações finais}

Ao buscarmos compreender o funcionamento da linguagem em uma prática de justiça restaurativa, da qual participaram, além dos coordenadores do procedimento, os sujeitos envolvidos no dano e suas respectivas comunidades de apoio, foi possível escutarmos vozes carregadas de vida, de histórias, de medos, mas, também, de memórias de futuro, que buscam transformar um situação de violência. Analisamos o caso Osório, enfocando na enunciação de sua mãe, Irene, que, construiu como resposta à situação de conflito, um medo pelo filho que assumiu características de aflição e preocupação para com esse outro, tornando-se obsessão por ele.

Encontramos, portanto, no círculo restaurativo um espaço de fala que sugere certa abertura para circulação de vozes historicamente rechaçadas do sistema oficial de justiça por carregarem, em alguma medida, elementos considerados subjetivos e fora da lógica racional e sistemática do contexto. Como isso, se encaminhará no âmbito do cotidiano do sistema penal não sabemos. Seja como for, como estudiosos de linguagem, investimos nas enunciações como caminho para construir leituras de mundo. Também como Geraldi, acreditamos, então, que um caminho a ser incluído em programas de estudos na área de linguagem seja aquele que aponta para as relações com a alteridade porque elas nos permitem "escutar o estranhamento" e "mostram-nos o que não mais conseguimos enxergar" (2010, p. 89).

Um enunciado, conforme o pensamento bakhtiniano, sempre responde a outro enunciado, de tal modo que, na corrente da comunicação discursiva, um enunciado é como um elo ligado a outros tantos enunciados. Dessa corrente, centramos nossa compreensão na voz de Irene, abordando-a como um ato responsável seu. Este trabalho é, assim, uma respos- 
ta que, como estudiosos de linguagem, oferecemos aos textos lidos. Outras respostas surgirão desse diálogo, mantendo viva a linguagem e os sentidos.

\section{(In)visible stories: the fear of the other as a responsible act}

\begin{abstract}
In problematizing social relations impaired by damages related to the practice of an infraction, we analyze statements that circulated in a restorative justice practice called "Restorative Circle", a very recent practice in the Brazilian context. Focusing on statements uttered by the mother of a youngster in conflict with the law, we explore the relationship she has established with her child as an alterity that constitutes and changes her. To do so, we analyzed the audio and video recording of a restorative circle present in the project of Rio Grande do Sul Justice for the 21st Century. The methodology of analysis is based on the theoretical-methodological orientations formulated by the $\mathrm{Ba}$ khtin Circle, developed according to the reading paradigm and the texts comparison. We notice that the statements of the young offender's mother suggest a strong fear for the child, such that her perception of the facts imprisons her in an unlimited responsibility for the child.
\end{abstract}

Keywords: Bakhtin. Restorative justice. Responsible act.

\section{Notas}

1 O presente trabalho retoma e aprofunda pesquisa anteriormente desenvolvida, na ocasião do curso de doutorado realizado pela primeira autora, sob orientação do segundo autor deste artigo.

2 Cabe destacar que não tivemos acesso nem aos sujeitos envolvidos direta ou indiretamente no caso de justiça restaurativa analisado, nem a dados que pudessem identificá-los. Quaisquer referências a esses sujeitos que venham sugerir suas identificações, como nomes, foram criados ficticiamente e não remetem a qualquer notícia do fato e a identificação real das pessoas.

3 Sobre os antecedentes que levaram à criação do J21, sugerimos leitura de materiais disponíveis na biblioteca on-line da iniciativa, disponível no site institucional desse projeto de justiça restaurativa.

\section{Referências}

BAKHTIN, M.M. Para uma filosofia do ato responsável. Tradução aos cuidados de Valdemir Miotello e Carlos Alberto Faraco. São Carlos, Pedro \& João Editores, 2010.

BAKHTIN, M. M/VOLOCHÍNOV, V.N. Marxismo e filosofia da linguagem. Problemas fundamentais do método sociológico na ciência da linguagem. Tradução de Michel Lahud \& Yara Frateschi Vieira, São Paulo: Editora Hucitec, 2009.

BRANCHER, L. Apresentação da coordenação do Projeto Justiça para o Século 21. In: BRANCHER, L. N.; SILVA, S. (Org.). Semeando justiça e pacificando violências: três anos de experiência da justiça restaurativa na capital gaúcha Porto Alegre: Nova Prova, 2008, p. 11-14.

BRANCHER, L. N.; AGUINSKY, B. G. Implementação de práticas de Justiça Restaurativa através do Projeto Justiça para o Século 21. Relato de prática ganhadora de menção honrosa no Prêmio Innovare, 2007. Disponível em:<http://justica21.web1119.kinghost.net/ 
j21.php?id=101\&pg=0\#. WuCFlYjwbIV > . Acesso em: 15 abr. 2018.

CARVALHO, S. C. L. de; LOBATO, J. H. de. C. Vitimização e processo penal. Jus $\mathrm{Na}$ vigandi, Teresina, ano 13, n. 1937, 20 out. 2008. Disponível em: <https://jus.com.br/ artigos/11854/vitimizacao-e-processo-penal>. Acesso em: 22 abr. 2018.

CERTEAU, M. de. A invenção do cotidiano: Artes de fazer. Tradução de Ephraim Ferreira Alves. 17 ed. Petrópolis: Vozes, 2011.

GERALDI, J. W. Ancoragens - Estudos bakhtinianos. São Carlos: Pedro \& João Editores, 2010.

. Heterocientificidade nos estudos linguísticos. In: GEGe. Palavras e contrapalavras: enfrentando questões da metodologia bakhtiniana. Caderno de Estudos IV Para Iniciantes. São Carlos: Pedro \& João Editores, 2012. p. 19-39.

GINZBURG, C. Mitos, emblemas, sinais: morfologia e história. Tradução de Federico Carotti. São Paulo: Companhia das Letras, 1989.

JACCOUD, M. Princípios, Tendências e Procedimentos que Cercam a Justiça Restaurativa. In: SLAKMON, C; DE VITTO, R. C. P.; PINTO, R. S. G. (Org.). Justiça Restaurativa. Brasília, Ministério da Justiça e Programa das Nações Unidaspara o Desenvolvimento (PNUD), 2005. p. 163-183. Disponível em: < <http://www.susepe.rs.gov. br/upload/1323798246_Coletania\%20JR. pdf>. Acesso em: 20 mar. 2018.

JUSTIÇA PARA O SÉCULO 21. O que é a Justiça para o Século 21? Copyright, 2011. Disponível em: <http://justica21.web1119. kinghost.net/j21.php?id=101\&pg=0\#.WuCFlYjwbIV>. Acesso em: 15 abr. 2018.

LÉVINAS, E. Humanismo do outro homem. Tradução de Pergentino S. Pivatto (coord.). Petropólis: Editora Vozes. 1993.

MCCOLD, P. \& WACHTEL T. Em busca de um paradigma: Uma teoria de justiça restau- rativa. In: INTERNATIONAL INSTITUTE FOR RESTORATIVE PRACTICES. XIII

CONGRESSO MUNDIAL DE CRIMINOLOGIA, 2003, Rio de Janeiro. Anais... Rio de Janeiro, 2003, p. 01-03. Disponível em:<https:// www.iirp.edu/eforum-archive/em-busca-de-um-paradigma-uma-teoria-de-justica-restaurativa>Acesso em: 04 abr. 2018.

MELLO, M. B. de. O amor em tempos de escola. São Carlos: Pedro \& João Editores, 2017.

NETO, P. S. Manual de Sociologia geral e jurídica. 4. ed. São Paulo: Saraiva, 2000

Por uma justiça restaurativa 'real e possível. In: ROLIM, M et al. Justiça Restaurativa: um caminho para os direitos humanos? Porto Alegre: IAJ, 2004. p. 33-43

PETRILLI, S. Em outro lugar e de outro modo. Filosofia da linguagem, crítica literária e teoria da tradução em, em torno e a partir de Bakhtin. Tradução de Daniela M. Mondardo et al. São Carlos: Pedro \& João Editores, 2013.

PONZIO, A. A revolução bakhtiniana: o pensamento de Bakhtin e a ideologia contemporânea. Traduzido de Valdemir Miotello (Coord.). São Paulo: Contexto, 2008.

Procurando uma palavra outra. Tradução de Valdemir Miotello et al. São Carlos: Pedro \& João Editores, 2010a.

- A concepção bakhtiniana do ato como dar um passo. In: BAKHTIN, M. M. Para uma filosofia do ato responsável. Tradução aos cuidados de Valdemir Miotello e Carlos Alberto Faraco. São Carlos, Pedro \& João Editores, 2010b. p.09-38.

. Dialogando sobre diálogo na perspectiva bakhtiniana. Tradução de Valdemir Miotello et al. São Carlos: Pedro \& João Editores, 2012.

SALES, L. M. de M. Mediação de conflitos: família, escola e comunidade. Florianópolis: Conceito Editorial, 2007. 
SAUSSURE, F. Curso de Linguística Geral.

Organizado por Charles Bally e Albert Sechehaye. Tradução de Antônio Chelini et al. São Paulo: Cultrix, 2006.

ZEHR, H. Trocando as lentes: um novo foco sobre o crime e a justiça. Tradução de Tônia Van Acker. São Paulo: Palas Athena, 2008. 